\title{
New process of preparation of pyrazolidine: synthesis, extraction and flow-sheet
}

\author{
A. El Hajj, A.J. Bougrine, and H. Delalu \\ Université de Lyon - Université Claude Bernard Lyon1, Laboratoire Hydrazines et Composés Énergétiques Polyazotés \\ UMR 5278 "UCBL/CNRS/CNES/SAFRAN-HERAKLES", 22 Avenue Gaston Berger- 69622 Villeurbanne Cedex
}

\section{Introduction}

A new process for the preparation of the pyrazolidine (PYRZ), by intramolecular Raschig way has been developed in our laboratory $[1,2]$. This work is divided into two parts: synthesis and extraction.

For the synthesis part: the reaction mechanism of the formation of pyrazolidine is carried out in two successive steps: the first involves the oxidation of 1,3diaminopropane (I, DAP, $\mathrm{C}_{3} \mathrm{H}_{10} \mathrm{~N}_{2}$ ) by sodium hypochlorite ( $\left.\mathbf{I I}, \mathrm{OCl}^{-}\right)$and formation of N,chloro-1,3diaminopropane (III, $\mathrm{C}_{3} \mathrm{H}_{9} \mathrm{~N}_{2} \mathrm{Cl}$ ). The second consists of a cyclization of $\mathrm{N}$,chloro-1,3-diaminopropane (III) leading to pyrazolidine (IV).

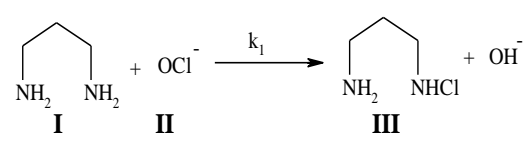

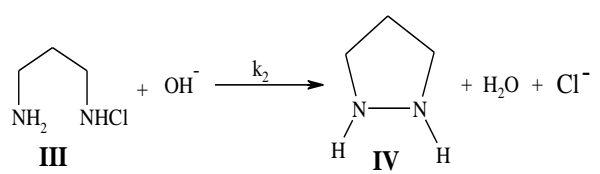

This synthesis requires an excess of the diaminopropane (DAP) reagent, in comparison to sodium hypochlorite ([DAP] $\left./\left[\mathrm{OCl}^{-}\right]=8\right)$, in order to increase the yield in pyrazolidine to $80 \%$.

For the extraction process, these non-stoichiometric synthesis conditions imply then the (pyrazolidine / diaminopropane) separation and the recycling of the excess amine upstream of the synthesis. However, this is particularly difficult because of the very close physicochemical properties of these two compounds. In particular, the boiling temperatures of pyrazolidine (411 $\mathrm{K}, 1$ bar) and 1,3-diaminopropane (409-410 K, 1 bar) differ by only 1 to $2 \mathrm{~K}$, which leads to avoid implementing distillation operations.

The chosen extraction strategy requires a sequence of two stages:

- The first stage is a liquid-liquid phase separation, generated by the addition of solid sodium hydroxide.
The optimization of these extraction conditions requires knowledge of phase equilibria in the quaternary system $\mathrm{H}_{2} \mathrm{O}-\mathrm{DAP}-\mathrm{PYRZ}-\mathrm{NaOH}$. The reaction solution is mainly composed of $27.2 \% \mathrm{w}$ in 1,3-diaminopropane, $3.7 \% \mathrm{w}$ in pyrazolidine, $5.7 \% \mathrm{w}$ $\mathrm{NaCl}, 0.1 \% \mathrm{w} \mathrm{NaOH}$ and $63.3 \% \mathrm{w}$ water, the amine will thus control the phenomenon of phase separation by solvent effect. We determined three isothermal sections $(289 \mathrm{~K}, 313 \mathrm{~K}$ and $323 \mathrm{~K})$ of the solid-liquidliquid isobaric ternary system $\mathrm{H}_{2} \mathrm{O}-\mathrm{DAP}-\mathrm{NaOH}$ by ITA [3] (Isoplethic Thermal Analysis) and acid-base titration.

- The second stage involves a selective precipitation of the two compounds in form of a salt by addition of hydrochloric acid. We determined and set three isothermal sections $(283 \mathrm{~K}, 298 \mathrm{~K}$ and $333 \mathrm{~K})$ of the isobaric solid-liquid ternary system $\mathrm{H}_{2} \mathrm{O}-\mathrm{DAP} .2 \mathrm{HCl}$ PYRZ.2HCl by ITA. A final purification by selective crystallization is necessary in order to obtain high purity PYRZ.

\section{Experimental}

\subsection{Apparatus}

In order to determine the different ternary system $\mathrm{H}_{2} \mathrm{O}$ DAP-NaOH and $\mathrm{H}_{2} \mathrm{O}-\mathrm{DAP} .2 \mathrm{HCl}-\mathrm{PYRZ} .2 \mathrm{HCl}$, several analytical methods were used: Isoplethic Thermal analysis (ITA) was used to determine the limit tie-line and chemical analysis were used to determine the binodal curves.

\subsection{Isoplethic thermal analysis}

This original method was developed in our laboratory [3]. It consists to follow the evolution of one or more physical properties of the system when its composition is modifying. For this study, liquid-solid equilibria were obtained by ITA, a device which permits to underline the transformations (crystallization, solubilization of a solid phase) of the system, in the course of addition of pure water for a constant reference temperature $T_{R}$. Thus, the 
molar and mass compositions of the mixture evolve in a linear way during the analysis and determine so an isoplethic section in the ternary system.

The fluctuation of the temperature is obtained using the following equation:

$\Delta \mathrm{T}=\left(\mathrm{S} . \Delta \mathrm{H}_{\mathrm{D}}-\Delta \mathrm{H}_{\mathrm{d}}\right) \cdot \mathrm{V} / \mathrm{K}$

Where:

S: solubility ( $\mathrm{g}$ of substance/liter of solvent)

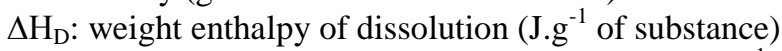

$\Delta \mathrm{H}_{\mathrm{d}}$ : partial volumic enthalpy of dissolution (J.L $\mathrm{L}^{-1}$ of substance)

$\mathrm{V}$ : rate of injection $\left(\mathrm{mL} \cdot \mathrm{h}^{-1}\right)$

$\mathrm{K}$ : cell constant $\left(\mathrm{W} . \mathrm{K}^{-1}\right)$

Figure 1 represents a thermogram obtained by ITA for a mixture whose composition $\mathrm{M}$ is located in the invariant ternary triangle. It shows the evolution of the temperature during the addition of pure water to the mixture $\mathrm{M}$.

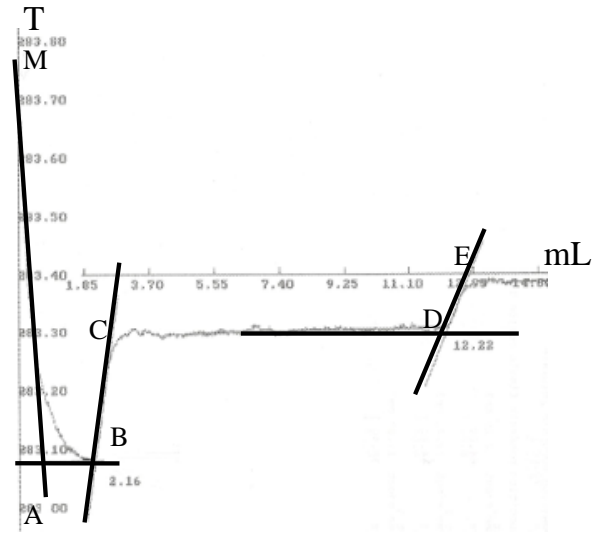

Figure 1. Thermogram obtained by ITA, $\mathrm{T}=\mathrm{f}\left(\mathrm{V}_{\mathrm{H} 2 \mathrm{O}}\right)$.

Segment MA corresponds to the equilibrium of the triphasic system M. From A to B, the addition of pure water implies the dissolution of the PYRZ.2 $\mathrm{HCl}$ salt. At point $\mathrm{B}$, the last crystals of dihydrochloride pyrazolidine disappear. Segment CD corresponds to the solid-liquid equilibrium between the saturated liquid and the DAP. $2 \mathrm{HCl}$ salt. At point D, the last crystals of dihydrochloride diaminopropane dissolve. Segment DE corresponds to the dilution of the system and the return to the equilibrium temperature. The $\mathrm{B}$ and $\mathrm{D}$ points correspond then to the end of dissolution of each salt. We denoted $\alpha$, the solubility of the DAP. $2 \mathrm{HCl}$ in pure water and $\beta$, the solubility of PYRZ.2HCl in pure water at $283 \mathrm{~K}$.

\section{Results}

\subsection{Determination of the isobaric solid-liquid ternary system H2O-DAP-NaOH}

Three isothermal sections (293, 313 and $323 \mathrm{~K}$ ) of the solid-liquid-liquid isobaric ternary system were determined.

Figure 2 show the isothermal sections obtained for the Water/Sodium Hydroxide/1,3-diaminopropane ternary system at $293 \mathrm{~K}$.

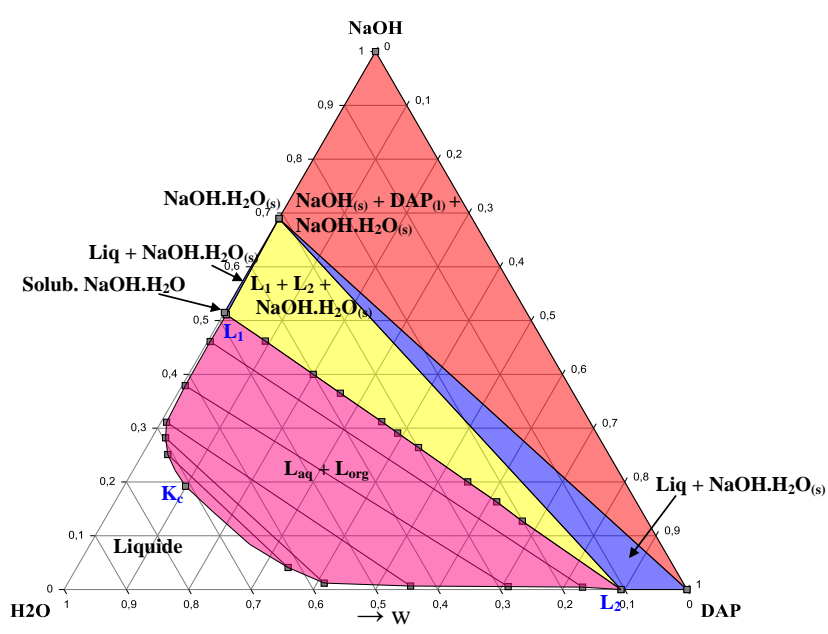

Figure 2. Solid-liquid-liquid isobaric ternary system $\mathrm{H}_{2} \mathrm{O}$-DAP$\mathrm{NaOH}$ at $\mathrm{T}=293 \mathrm{~K}$.

All isotherms studied (293, 313 and $323 \mathrm{~K})$ are characterized by 6 domains:

- a liquid monophasic domain in the water rich part

- one biphasic domain $\left(\mathrm{L}_{\mathrm{aq}}+\mathrm{L}_{\mathrm{org}}\right)$

- one triphasic three-phase triangle $\left(\mathrm{L}_{1}+\mathrm{L}_{2}+\mathrm{NaOH}_{2} \mathrm{H}_{2} \mathrm{O}_{(\mathrm{S})}\right.$

- two biphasic domains $\left(\mathrm{L}+\mathrm{NaOH} \cdot \mathrm{H}_{2} \mathrm{O}_{(\mathrm{s})}\right)$

- one triphasic three-phase triangle $\left(\mathrm{NaOH}_{(\mathrm{s})}+\right.$ $\left.\mathrm{NaOH} . \mathrm{H}_{2} \mathrm{O}_{(\mathrm{s})}+\mathrm{Dap}_{(\mathrm{l})}\right)$.

The evolution of liquid compositions of invariant mass versus temperature is presented in table1.

Table1. Massic compositions of the invariant liquid $\mathrm{Li}$ as function of the temperature.

\begin{tabular}{|c|c|c|c|c|}
\hline \multirow{2}{*}{$\mathrm{T}(\mathrm{K})$} & \multicolumn{2}{|c|}{$\mathrm{L}_{1}$ (aqueous phase) } & \multicolumn{2}{c|}{$\mathrm{L}_{2}$ (organic phase) } \\
\cline { 2 - 5 } & $\begin{array}{c}\mathrm{W} \\
(\mathrm{DAP})\end{array}$ & $\begin{array}{c}\mathrm{W} \\
(\mathrm{NaOH})\end{array}$ & $\begin{array}{c}\mathrm{W} \\
(\mathrm{DAP})\end{array}$ & $\begin{array}{c}\mathrm{W} \\
(\mathrm{NaOH})\end{array}$ \\
\hline 293 & 0.005 & 0.511 & 0.894 & 0 \\
\hline 313 & 0.016 & 0.549 & 0.908 & 0.007 \\
\hline 323 & 0.033 & 0.564 & 0.923 & 0.012 \\
\hline
\end{tabular}

These results show the ineffectiveness of a temperature rise in the optimization of separation conditions by salting out with sodium hydroxide. The demixing temperature was set at $293 \mathrm{~K}$. With this method, we can concentrate the hydrazine and the amine reagent, in particular at $293 \mathrm{~K}$, we obtain an organic phase of: 15.4\%w PYRZ, 71.7\%w DAP and $12.9 \% \mathrm{w} \mathrm{H}_{2} \mathrm{O}$.

\subsection{Determination of the isobaric ternary system soli-solid-liquid H2O-DAP.2HCl-PYRZ.2HCI}

Three isothermal sections (283, 293 and $333 \mathrm{~K})$ of the solid-solid-liquid isobaric ternary system were determined. Figure 3. show the isothermal sections obtained for the $\mathrm{H}_{2} \mathrm{O}$-DAP.2HCl-PYRZ.2HCl ternary system at $293 \mathrm{~K}$. 


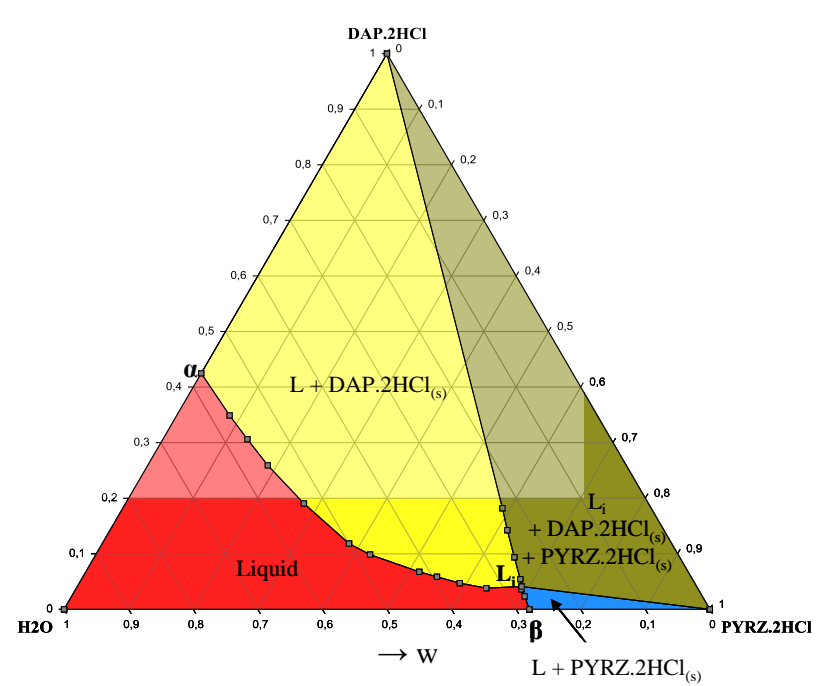

Figure3. Solid-liquid ternary system $\mathrm{H}_{2} \mathrm{O}-\mathrm{DAP} .2 \mathrm{HCl}$ $\mathrm{PYRZ} .2 \mathrm{HCl}$ at $\mathrm{P}=1$ bar and $\mathrm{T}=333 \mathrm{~K}$.

We denoted $\alpha$, the solubility of the DAP. $2 \mathrm{HCl}$ in pure water and $\beta$, the solubility of PYRZ.2 $\mathrm{HCl}$ in pure water at $333 \mathrm{~K}$ (the two binary diagrams Water-PYRZ.2HCl and Water-DAP.2HCl were determined by ATI, combined with DSC measurements).

All the isotherms studied are characterized by 4 domains:

- a liquid monophasic domain in the water rich part.

- one biphasic domain of crystallization of DAP. $2 \mathrm{HCl}$

- one biphasic domain of crystallization of PYRZ.2HCl

- one triphasic three-phase triangle $\left(\mathrm{L}_{\mathrm{i}}+\mathrm{DAP} .2 \mathrm{HCl}+\right.$

PYRZ.2HCl).

For all the temperature range studied ( 283 to $333 \mathrm{~K}$ ), the isotherms show a very large crystallization domain of the DAP.2HCl and a very narrow domain for the crystallization of PYRZ.2HCl, due to the high solubility of PYRZ.2HCl in water. This asymmetry leads to the elimination of the majority of DAP. $2 \mathrm{HCl}$ by selective precipitation. The massic compositions of the invariant liquid, as function of the temperature, are presented in the table2.

Table2. Massic compositions of the invariant liquid $\mathrm{Li}$ as function of the temperature.

\begin{tabular}{|c|c|c|c|}
\hline $\mathrm{T}$ & $\% \mathrm{w}$ & $\% \mathrm{w}$ & $\% \mathrm{w}$ \\
$/ \mathrm{K}$ & PYRZ.2HCl & DAP.2HCl & $\mathrm{H}_{2} \mathrm{O}$ \\
\hline 283 & 68,2 & 2,9 & 28,9 \\
\hline 298 & 68,8 & 4,1 & 27,1 \\
\hline 333 & 71 & 7,5 & 21,5 \\
\hline
\end{tabular}

By this method, we can thus recycle a majority of the DAP reagent used in the synthesis, in particular, at 283 $\mathrm{K}$, it is possible to recycle $97 \%$ of the diaminopropane involved in the synthesis.

We obtain then an aqueous solution of pyrazolidine dihydrochloride titrating $68 \% \mathrm{w}$ PYRZ.2 $\mathrm{HCl}$. A final purification by selective crystallization is necessary in order to obtain high purity PYRZ.

\section{Conclusion}

The synthesis process of pyrazolidine by the Raschig way is shown in figure 4 .

a) Reaction of diaminopropane with sodium hypochloride in aqueous medium in order to form pyrazolidine $(\mathrm{p}=$ $\left.[\mathrm{DAP}]_{0} /\left[\mathrm{OCl}^{-}\right]_{0}=8\right)$.

b) Demixing of the reaction mixture obtained in step (a) by addition of anhydrous $\mathrm{NaOH}$ at $\mathrm{T}=293 \mathrm{~K}$ and recovering of the organic phase.

c) Precipitation of the DAP. $2 \mathrm{HCl}$ salt by addition of hydrochloric acid at $\mathrm{T}=283 \mathrm{~K}$.

d) Evaporation of excess water and filtration of the DAP. $2 \mathrm{HCl}$ salt.

e) Neutralization of the DAP.2HCl by addition of two equivalents of sodium hydroxide in order to obtain molecular diaminopropane which is then recycled after distillation.

e) Evaporation and filtration of the aqueous solution of pyrazolidine dihydrochloride.

g) Final purification by selective crystallization in order to obtain high purity PYRZ.

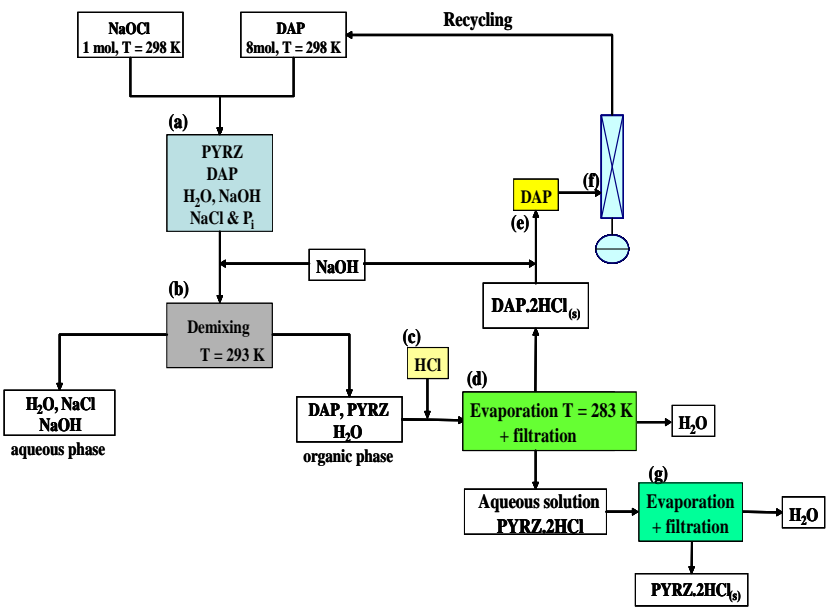

Figure4. Process flow-sheet.

\section{References}

1. A. El Hajj, A.J. Bougrine, H. Delalu, Chemical Engineering Transactions 2431 (2011)

2. A. El Hajj, A.J. Bougrine, H. Delalu, Chemical Engineering Transactions 241543 (2011)

3. J. Berthet, J.J. Counioux. Brevet F9313402, (1993) 